Article

\title{
An Extended Fourier Approach to Improve the Retrieved Leaf Area Index (LAI) in a Time Series from an Alpine Wetland
}

\author{
Xingwen Quan ${ }^{1}$, Binbin He ${ }^{1, *}$, Yong Wang ${ }^{1,2}$, Zhi Tang ${ }^{1}$ and Xing $\mathrm{Li}^{1}$
}

1 School of Resources and Environment, University of Electronic Science and Technology of China, Chengdu 611731, China; E-Mails: quanxw7@gmail.com (X.Q.); wangy2012@uestc.edu.cn (Y.W.); 13980476627@163.com (Z.T.); zxwlxty@163.com (X.L.)

2 Department of Geography, Planning and Environment, East Carolina University, Greenville, NC 27858, USA

* Author to whom correspondence should be addressed; E-Mail: binbinhe@uestc.edu.cn; Tel.: +86-28-6183-1586.

Received: 14 November 2013; in revised form: 5 January 2014 / Accepted: 17 January 2014 / Published: 29 January 2014

Abstract: An extended Fourier approach was presented to improve the retrieved leaf area index $\left(\mathrm{LAI}_{\mathrm{r}}\right)$ of herbaceous vegetation in a time series from an alpine wetland. The retrieval was performed from the Aqua MODIS 8-day composite surface reflectance product (MYD09Q1) from day of year (DOY) 97 to 297 using a look-up table (LUT) based inversion of a two-layer canopy reflectance model (ACRM). To reduce the uncertainty (the ACRM inversion is ill-posed), we used NDVI and NIR images to reduce the influence of the soil background and the priori information to constrain the range of sensitive ACRM parameters determined using the Sobol's method. Even so the uncertainty caused the LAIr versus time curve to oscillate. To further reduce the uncertainty, a Fourier model was fitted using the periodically LAIr results, obtaining LAIF. We note that the level of precision of the LAIF potentially may increase through removing singular points or decrease if the LAI data were too noisy. To further improve the precision level of the LAIr, the Fourier model was extended by considering the LAIr uncertainty. The LAI $\mathrm{r}$, the LAI simulated using the Fourier model, and the LAI simulated using the extended Fourier approach $\left(\mathrm{LAI}_{\mathrm{eF}}\right)$ were validated through comparisons with the field measured LAI. The $\mathrm{R}^{2}$ values were $0.68,0.67$ and 0.72 , the residual sums of squares (RSS) were 3.47, 3.42 and 3.15, and the root-mean-square errors (RMSE) were 0.31, 0.30 and 0.29, respectively, on DOY 177 (early July 2011). In late August (DOY 233), the $\mathrm{R}^{2}$ values were $0.73,0.77$ and 0.79 , the RSS values were 38.96, 29.25 and 27.48 , and the RMSE values were $0.94,0.81$ and 0.78 , respectively. The results 
demonstrate that the extended Fourier approach has the potential to increase the level of precision of estimates of the time varying LAI.

Keywords: alpine wetland; extended Fourier approach; ill-posed inversion problem; leaf area index; uncertainty

\section{Introduction}

The use of remotely sensed optical data over large areas to quantitatively infer key biophysical and biochemical parameters of vegetation, such as the leaf area index (LAI), has been a popular application of remote sensing [1-3]. The LAI is a critical structural characteristic that affects the biophysical and biochemical processes of vegetation canopies and the exchange processes of energy and matter between the land surface and the lower atmosphere [4-6]. The approaches used to retrieve LAI generally include combined empirical and statistical approaches and the inversion of a physical canopy reflectance model. In the former, a technique is used to link the LAI to the associated sensitive spectral reflectance or to vegetation indices (VI) based on field data. These approaches are simple and computationally efficient but are regarded as sensor-specific, site-dependent, and vary significantly over time and space [7-9]. The inversion approach is promising because it is based on physical models [1,4,7]. Unfortunately, the ill-posed inversion problem [10] is prevalent in the model-based retrieval procedure and results in uncertainty in the retrieved LAI. The use of a priori information has been demonstrated to alleviate the ill-posed inversion problem $[1,6,9]$.

Vegetation parameters, including LAI, that are retrieved simultaneously may not meet the requirements of specific applications, such as the classification of vegetation types [11], vegetation growth changes and phenology [12-15]. However, due to cloud interference and image-specific problems that result in missing data at aperiodic times of the year, remotely sensed imagery may not form high-quality time series [16]. Because of the poor-quality data and ill-posed inversion problems, the uncertainty in the values of parameters retrieved at a particular time can be large. When the parameters are plotted versus time, the curves have discrete and oscillating features. Thus, a reliable method is needed to smooth the curves.

One way to smooth these curves is the data assimilation technique [3,17], which has been used to integrate observed data with models in hydrology [18], crop science [19], oceanography [20], morphodynamics [21], and air quality modeling [22,23]. The data assimilation technique requires a dynamic model. Models such as WOFOST [24,25], DSSAT [26], and SWAP [27] have been widely used to simulate and forecast vegetation growth or the growth state and yield of crops. Because the uncertainty in the observed data, the dynamic model, and the background parameters of the model inputs are all considered, the technique can be used to reliably smooth curves of target parameters [28]. Unfortunately, the large set of input parameters required by the technique is difficult to obtain. Different types of vegetation usually require different inputs and models [24]. In addition, the technique can be time-consuming [28].

If the dataset is periodic, another way to smooth multi-temporal curves or solve missing data problems is the Fourier model [16]. The Fourier model is a specific infinite series and can be tailored to 
any period, baseline, and amplitude. As the number of harmonics used increases, the Fourier model can converge to any smooth periodic function. The model has been successfully used in the classification of vegetation types [15] and photosynthetic activity over the growing season [12-14,29,30]. However, the aforementioned studies are primarily focused on smoothing the normalized difference vegetation index (NDVI) [31] and seldom on smoothing parameters retrieved through physically based models. The Fourier model has the ability to smooth multi-temporal curves and overcome missing data problems. However, the model cannot improve the precision of retrieved parameters, whereas the assimilation technique potentially can. Thus, this study considers an extended Fourier approach in which the advantage of the assimilation technique that is able to deal with the uncertainty in the retrieved parameters. In particular, we focus on the improvement of the retrieved LAI (LAIr) of herbaceous vegetation in a one-year time series from an alpine wetland. The study includes three major steps. The LAIs from different time periods are retrieved using a two-layer canopy reflectance model (ACRM), the Aqua MODIS 8-day composite surface reflectance product (MYD09Q1) from DOY 97 to 297, and a look-up table (LUT) algorithm. The Fourier model is then fitted to simulate the variation of LAI values in the time series using the $\mathrm{LAI}_{\mathrm{r}}$ and the least squares method. Finally, the Fourier model is extended to quantify the uncertainty in the LAI . Therefore, the precision level of the fitted LAI curve is improved. The LAI , fitted LAI, and the improved LAI are validated using the LAI values measured on DOY 177 (early July 2011) and 233 (late August). Details about the method are given next.

\section{Method}

\subsection{The Schemes of LAI Retrieval}

The inversion is by nature ill-posed [10]. Three strategies are implemented in the alleviation of the ill-posed problem [9]. (I) To reduce the influence of the soil background, we use the normalized difference vegetation index (NDVI) to retrieve the LAI for sparse vegetation and the near-infrared (NIR) reflectance for dense vegetation; (II) A sensitivity analysis of the ACRM at red (RED) and NIR wavelengths is conducted using Sobol's method [32] to determine the sensitive parameters; (III) The priori information collected from fieldwork is used to constrain the range of each sensitive parameter. The LAI is then retrieved from the time series by inverting the ACRM using the LUT algorithm and the MYD09Q1 data from DOY 97 to 297.

\subsubsection{Radiative Transfer Model}

The ACRM radiative transfer model is used [33]. The model assumes that the vegetation canopy consists of a main homogeneous layer of vegetation and a thin layer of vegetation on the ground surface. Both vegetation layers are characterized by a similar set of phytometric parameters that control the optical properties of the leaves. The model operates in the spectral region of 400-2,500 nm, and the spectral resolution is $1 \mathrm{~nm}$, which is appropriate for direct and inverse problems [33]. The model input parameters are briefly discussed below.

With the Âith the turbidity equation [34], the turbidity coefficient $(\beta)$ is used to compute the diffuse fraction of incoming radiation. The Markov clumping parameter $\left(S_{z}\right)$ ranges from 0.4 , which represents a significantly clumped plant canopy, to 1.0, which represents a homogeneous canopy of randomly 
positioned leaves [6]. The soil background reflectance $\rho_{\text {soil }}(\lambda)$ can be described by a function that is the combination of four basis vectors, $\varphi_{i}(\lambda)\left(i=1,2,3\right.$, and 4). However, $\varphi_{1}(\lambda)$ and $\varphi_{2}(\lambda)$ are sufficient to describe the spectral variability of the reflectance because both account for nearly $94.2 \%$ of the spectral variability [35]. Thus,

$$
\rho_{\text {soil }}(\lambda) \approx s 1 \varphi_{1}(\lambda)+s 2 \varphi_{2}(\lambda)
$$

In addition, weight $s 2$ is related to $s 1[6,36]$. The angular distribution of leaves, which is described by the leaf inclination $\left(\theta_{m}\right)$ and the eccentricity $\left(e_{l}\right)$, is an elliptically distributed function [37]. The parameter $\theta_{m}$ represents the inclination angle, with $\theta_{m}=0$ indicating a planophile canopy and $\theta_{m}=90$ denoting an erectophile canopy. The parameter $e_{l}$ characterizes the leaf orientation, and $0 \leq e_{l} \leq 1 ; e_{l}=0$ represents a spherical orientation, and $e_{l}=1$ represents a fixed inclination angle [38]. The field measured leaf inclination angle $\left(\theta_{l}\right)$ is used to fit $\theta_{m}$ and $e_{l}$ by utilizing a model that is based on the elliptical distribution function $g_{l}\left(\theta_{l}\right)[36,39]$

$$
g_{l}\left(\theta_{l}\right)=\frac{b}{\sqrt{1-e_{l}^{2} \cos ^{2}\left(\theta_{l}-\theta_{m}\right)}}
$$

where $b$ can be determined as

$$
b=\frac{e_{l}}{\left[\cos \theta_{m} \ln \left(\frac{\cos \eta+\sin v}{\cos v-\sin \eta}\right)-\sin \theta_{m}(\eta-v)\right]}
$$

with

$$
\begin{gathered}
\eta=\sin ^{-1}\left(e_{l} \cos \theta_{m}\right) \\
v=\sin ^{-1}\left(e_{l} \sin \theta_{m}\right)
\end{gathered}
$$

The leaf optics model PROSPECT [40] is added to the ACRM and used to calculate the leaf reflectance and transmittance from $400 \mathrm{~nm}$ to $2,500 \mathrm{~nm}$ at a spectral resolution of $1 \mathrm{~nm}$. The biochemical parameters used as model inputs are expressed as multiple fractions of the dry matter of leaves [33]. The five key parameters included in the model are the leaf mesophyll structure parameter $(N)$, the chlorophyll $a$ and $b$ content $\left(C_{a b}\right)$, the equivalent water thickness $\left(C_{w}\right)$, the dry matter content $\left(C_{m}\right)$, and the leaf brown pigment $\left(C_{b p}\right)$. Of these, $C_{w}$ has a large influence on the shortwave infrared but only a slight influence at the NIR and RED wavebands. $C_{b p}$ represents the degree of leaf senescence and the light being absorbed by non-chlorophyll pigments and may vary from 0 , representing no light absorption, to 6, which indicates maximum light absorption [6].

\subsubsection{Sensitivity of NDVI and NIR Reflectance to LAI}

The NDVI is generally sensitive to LAIs between 0 and 4.0 (Figure 1a) and becomes saturated as the LAI continues to increase. Thus, using NDVI images can cause significant uncertainty in retrieving high LAI values. The NIR reflectance is sensitive even at LAI values greater than 4.0 (Figure 1b). Figure 1, the influence of soil background ( $s 1)$ exists, but the influence differs. Thus, to alleviate the ill-posed inversion and to reduce the uncertainty in $\mathrm{LAI}_{\mathrm{r}}$, one can use NDVI images to retrieve the LAI when LAI $<4.0$, and NIR images to retrieve the LAI of high values. Based on field measurement, 
the NDVI $=0.8$ is selected as the threshold. When $0<\mathrm{NDVI}<0.8$, the LAI is retrieved by the NDVI, while $0.8 \leq \mathrm{NDVI}<1.0$ the LAI is retrieved by NIR.

Figure 1. Sensitivity of normalized difference vegetation index (NDVI) to leaf area index (LAI) (a) and of NIR reflectance to LAI (b) by running two-layer canopy reflectance model (ACRM) forward at different values of $s 1$.
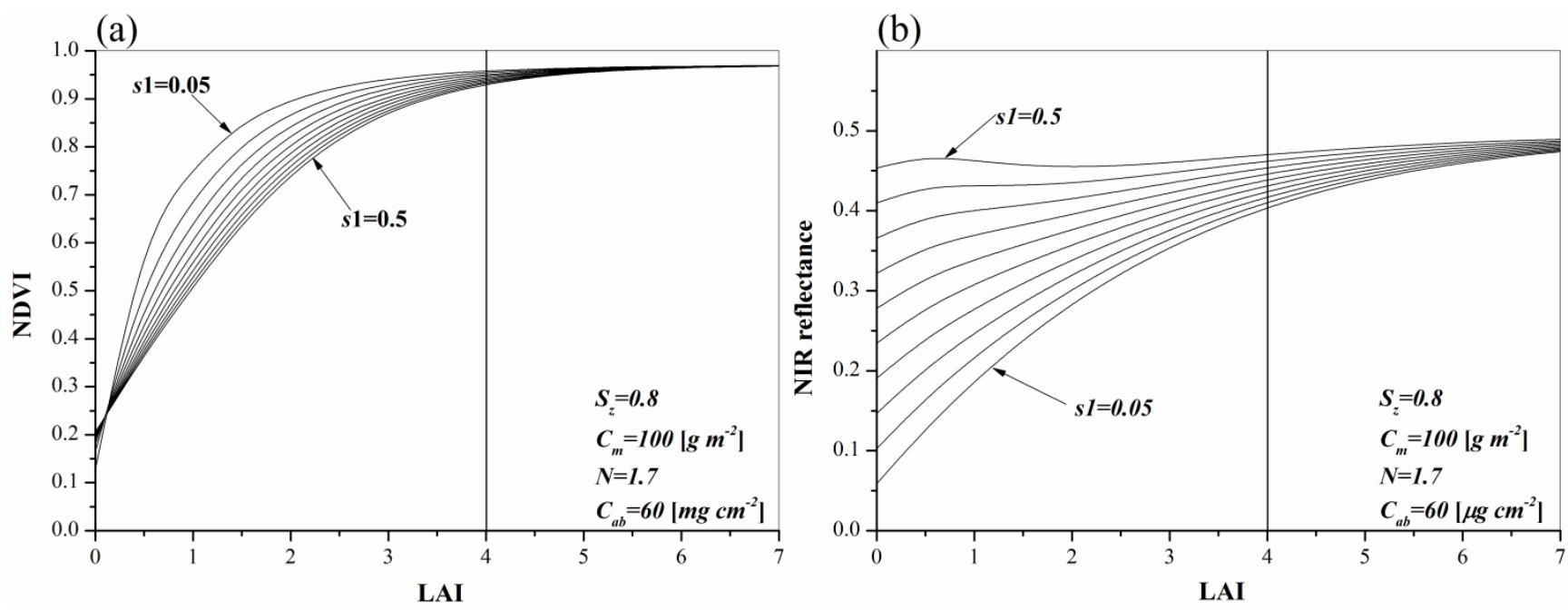

\subsubsection{Sensitivity Analysis of ACRM}

The sensitivities of different model parameters are different at RED and NIR wavelengths. To mitigate the ill-posed inversion problem, we set the sensitive parameters as free variables and the insensitive parameters as empirical values. Sobol's method [32] is used in the sensitivity analysis. The method is based on variance decomposition [41] and is a global and model-independent sensitivity analysis. The method is superior to traditional local methods that examine sensitive parameters one at a time and the method is robust [42].

The main idea behind Sobol's method for the computation of sensitivity indices is to decompose the function or model of $f\left(x_{1}, \ldots, x_{n}\right)$ into summands with increasing dimensionality as

$$
f\left(x_{1}, \ldots, x_{n}\right)=f_{0}+\sum_{i=1}^{n} f_{i}\left(x_{i}\right)+\sum_{i=1}^{n} \sum_{j=i+1}^{n} f_{i j}\left(x_{i}, x_{j}\right)+\ldots+f_{1,2, \ldots, n}\left(x_{1}, \ldots, x_{n}\right)
$$

where $x_{1}, \ldots, x_{n}(n=2,3,4 \ldots)$ are model input parameters. To hold $f_{0}$ be a constant, the integrals of every summand over any of its own variables must be zero. The individual summands are then mutually orthogonal [41]. Additionally, the decomposition is unique. The total variance $D$ of $f(X)$ is defined as

$$
D=\int_{K^{n}} f^{2}(X) d X-f_{0}^{2}
$$

where $K^{n}(n=1,2,3, \ldots)$ represents the $n$-dimensional unit hyperspace. Assuming that the parameters are mutually orthogonal, $D$ is decomposed as

$$
D=\sum_{i=1}^{n} D_{i}+\sum_{i=1}^{n} \sum_{j=i+1}^{n} D_{i j}+\ldots+D_{1,2, \ldots, n}
$$


Therefore, the variance of the individual parameters and the interactions between the parameters that contribute to the total variance in the output can be determined. The contributions are characterized by Sobol's sensitivity indices $\left(S_{i}\right)[43]$ as

$$
\begin{aligned}
& \text { First order: } S_{i}, S_{i}=D_{i} / D \\
& \text { Total: } S_{T i}, S_{T i}=1-D_{\sim i} / D
\end{aligned}
$$

The first order index $S_{i}$ is a measurement of the individual parameter $x_{i}$ to the total model variance. The partial variance of $D_{i}$ in Equation (9) is called the "main effect" of $x_{i}$ on $f\left(x_{1}, \ldots, x_{n}\right) . S_{T i}$ is the total sensitivity indices (TSI) of $x_{i}$, and " $\sim$ " means "complementary".

\subsubsection{LAI Retrieval Using the LUT Algorithm}

The LUT algorithm is generally computationally efficient [44]. It contains three steps. The first is to set up the table by running the ACRM. In the table, different combinations of input parameters are linked to the model outputs. If the range of the sensitive parameters is too wide, the table will be very large. The uncertainty in the LAIr increases because some cases may not be true. For example, the LAI is always positive for vegetated surfaces. A zero or negative value of LAI in the LUT can cause large uncertainty in the LAI . The priori information has been shown to be useful in constraining the range of sensitive parameters.

The cost function that links the simulated and observed values is then established. The function is expressed as

$$
\chi_{i}=\sqrt{\left(\rho_{j}^{*}-\rho_{i}\right)^{2}} \leq \mathcal{E}
$$

where $\rho_{j}^{*}$ is the $j$ th simulated value in the LUT, $\rho_{i}$ is the $i$ th observed value, and $\varepsilon$ is a threshold value. The final step is to retrieve the target parameters based on the satellite images, the constructed LUT, and the cost function. If $\chi_{i} \leqslant \varepsilon$, the combination of model input parameters can be regarded as the retrieved result. However, the ill-posed inversion problem still exists because the condition can be met in many cases for a simulated $\rho_{j}{ }^{*}$. The retrieved result is generally in a range of LAI values with different frequencies. The mean LAI or the LAI with the maximum frequency can be used to represent the LAIr if the retrieved LAI range is normally distributed. However, for the case of a non-normal distribution, it is more reliable to use the LAI with the maximum frequency (LAImax-fre) to represent the LAIr. It should be noted that more combinations of model parameters meet Equation (11) for the middle LAIr than for the LAIr value closest to the given boundary. This indicates that the scheme of LAI retrieval used in this study should have higher precision for low and high LAI values than values in the middle of the range.

\subsection{The Extended Fourier Approach}

Due to the periodicity in the LAI chronological series, the LAI versus time curves can be fitted using the Fourier model. The model is generally expressed as

$$
\operatorname{LAI}\left(a_{0}, a_{i}, b_{i}\right)=a_{0}+\sum_{i=1}^{n}\left[a_{i} \times \sin \left(i \times t \times \frac{2 \pi}{T}\right)+b_{i} \times \cos \left(i \times t \times \frac{2 \pi}{T}\right)\right]
$$

where $a_{0}, a_{i}$, and $b_{i}(i=1,2,3, \ldots, n)$ are unknown and should be fitted, $n$ is the number of free variables and ranges from 3 to $5, t$ is the DOY, and $T$ is the period. 
The Fourier model coupled with polynomials (non-classical harmonic methods) can reduce the "roughness" in the fitting procedure [16,30]. Thus, the Fourier model is modified to improve its ability to smooth the "rough" LAI versus time curve. The modification is

$$
L A I_{p}\left(a_{0}, a_{i}, b_{i}, c_{j}\right)=a_{0}+\sum_{i=1}^{n}\left[a_{i} \times \sin \left(i \times t \times \frac{2 \pi}{T}\right)+b_{i} \times \cos \left(i \times t \times \frac{2 \pi}{T}\right)\right]+\sum_{j=1}^{k}\left[c_{j} \times\left(\frac{t}{T}\right)^{j}\right]
$$

where $c_{j}$ (with $j=1,2, \ldots, k$ ) is unknown and needs to be fitted, and $k$ is similar to $n$. Based on experience with the fitting procedure, $n$ equals 4 , and $k$ is equal to 2 . Because the LAI chronological series has a period of one year and the data used are MYD09Q1, $T=46$. In particular, because the DOYs range from 13 to 42 in this experiment, the period is not one year. The Fourier model can be normalized as

$$
L A I_{p, n}\left(a_{0}, a_{i}, b_{i}, c_{j}\right)=a_{0}+\sum_{i=1}^{n}\left[a_{i} \times \sin \left(i \times t \times \frac{2 \pi}{T}\right)+b_{i} \times \cos \left(i \times t \times \frac{2 \pi}{T}\right)\right]+\sum_{j=1}^{k}\left[c_{j} \times\left(\frac{t-13}{42-13}\right)^{j}\right]
$$

Because each DOY is related to one Equation (14), the number of equations will be much greater than the number of unknown parameters. The parameters will be overdetermined. Thus, the optimal solution can be obtained using the method of least squares

$$
J(u)=\frac{1}{2} \sum_{t}\left(L A I_{p, n}(u)_{s, t}-L A I_{r, t}\right)^{T}\left(L A I_{p, n}(u)_{s, t}-L A I_{r, t}\right)
$$

where $J(u)$ is the cost function, $u$ is the vector of variables that should be fitted, $L A I_{p, n}(u)_{s, t}$ is the LAI fitted using the Fourier model $\left(\mathrm{LAI}_{\mathrm{F}}\right)$, and $L A I_{r, t}$ is the dataset of $\mathrm{LAI}_{\mathrm{r}}$ on the $t$ th DOY. Due to the ill-posed inversion problem, the LAI $\mathrm{r}_{\mathrm{r}}$ dataset normally contains singular points. The fitting procedure can remove these points and improve the level of precision of the LAIr. However, if the dataset contains large uncertainty, the fitting procedure may reduce the level of precision of the LAIr.

Using the data assimilation technique, the uncertainty in the observed data can be taken into account to improve the simulation results. Thus, the uncertainty can be included in the fitting procedure to possibly improve the precision level of the $\mathrm{LAI}_{\mathrm{r}}$ in the time series. Based on this consideration, $J(u)(15)$ is further extended by taking into account the uncertainty in $\mathrm{LAI}_{\mathrm{r}}$ as $J(u)_{e}$

$$
J(u)_{e}=\frac{1}{2} \sum_{t}\left(L A I_{p, n, u}(u)_{s, t}-L A I_{r, t}\right)^{T} L A I_{\text {uncerta int } y, t}^{-2}\left(L A I_{p, n}(u)_{s, t}-L A I_{r, t}\right)
$$

where $L A I_{p, n, u}(u)_{s, t}$ is the $\mathrm{LAI}_{\mathrm{r}}$ updated through the extension (LAI $\left.\mathrm{eF}\right), L A I_{\text {uncertainty, }}$ is the uncertainty in the retrieved $L A I_{s, t}$, and $n$ is the total number of $L A I_{r}$ values in one year. Because the $L A I_{\text {max }}$-fre is set as the $\mathrm{LAI}_{\mathrm{r}}$ (Section 2.1.4), the $L A I_{\text {uncertainty }}$ can be defined as

$$
L A I_{\text {uncertainty }}=\sqrt{\sum_{t}\left(L A I_{r, t}-L A I_{\text {max }-f r e}\right)^{2} f\left(L A I_{r, t}\right)}
$$

where $f\left(L A I_{r, i}\right)$ is the $t$ th frequency of the $L A I_{r, t .}$. Therefore, every term in Equation (16) is defined, and the equation is solved by the method of least squares.

\section{Study Area and Data}

\subsection{Study Area}

The study area is located in the Wutumeiren prairie (latitude $36^{\circ} 46^{\prime}$ to $37^{\circ} 30^{\prime} \mathrm{N}$, longitude $92^{\circ} 18^{\prime}$ to $93^{\circ} 24^{\prime} \mathrm{E}$ ), Qinghai Province, China (Figure 2). It covers an area of $\sim 1,174 \mathrm{~km}^{2}$ and has an average 
elevation of $2900 \mathrm{~m}$. The prairie is surrounded by the Gobi Desert. The Wutumeiren River is the main water source in the area. The climate includes annual rainy and dry seasons; the rainy season is normally from July to August, and the rest of the year is dry. The soil is characterized by high salinity and alkalinity. Thus, only a few types of adaptable and strong vegetation can grow. The vegetation is primarily composed of reeds. Due to variations in the soil moisture content, the reeds are clumped in some areas and are homogenous in others. Mixtures of grasses, shrubs, and trees are located at the edges of the prairie. They were planted to prevent the spread of the desert into the prairie. The edges of the prairie are not included in the study.

Figure 2. The study area (Wutumeiren prairie). The color composite Landsat5 image is TM4 (red), TM3 (green), and TM2 (blue). Green points represent the sampling plots from 6 to 9 July 2011, and the yellow points represent sampling plots between 26 and 29 August 2011.

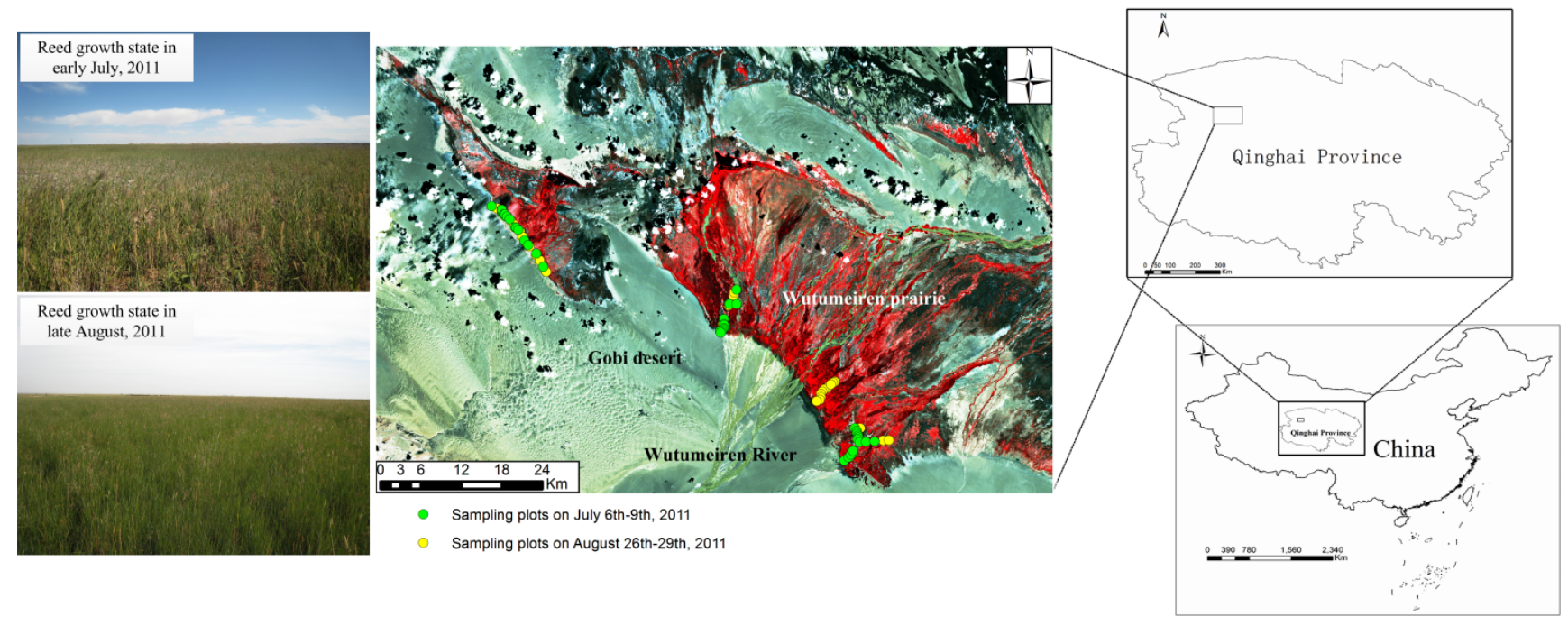

\subsection{Satellite Images and Field Measurements}

Thirty MYD09Q1 images (http://glovis.usgs.gov/) with a spatial resolution of $250 \mathrm{~m}$ were collected from DOY 97 to 329. The images were converted to surface reflectance. Each image was geometrically rectified into Universal Transverse Mercator (UTM) coordinates (zone 46) with the WGS-84 datum. The fieldwork was conducted from 7 to 9 July 2011 and from 26 to 29 August 2011 (Figure 2). An LAI-2000 instrument (http://www.licor.com) was used to measure the canopy LAI under clear sky conditions at low solar elevation angles and at approximately the same local time each day. To prevent direct sunlight from shining on the sensor, a $45^{\circ}$ view restrictor was used, and the Sun was kept behind the operator. Sample plots $(30 \mathrm{~m} \times 30 \mathrm{~m})$ were selected in homogenous reed areas (Figure 2), and their locations were recorded using global positioning system (GPS) units. Ninety-two plots were sampled. Within each sample plot, which was smaller than a single pixel, three subplots $(1 \mathrm{~m} \times 1 \mathrm{~m})$ were randomly selected and measured. The mean LAI value of the subplots was used to represent the measured LAI. It should be noted that of eight plots, they were not apart far enough from each other. Three plots were within one $250 \mathrm{~m} \times 250 \mathrm{~m}$ pixel, and another three plots were within a second pixel. In these two cases, the LAI was measured nine times per pixel. The LAI values of the nine subplots within each pixel were very similar. In four cases, two plots were within one pixel. Six LAIs were measured per 
pixel, and the LAIs were nearly the same. The similarity of the measured LAI values in each pixel indicated the homogeneity of the sampled area.

\section{Results and Analysis}

\subsection{Sensitivity of ACRM Inputs to RED and NIR Reflectance and Parameterization of the Inputs}

The parameters LAI, $S_{L}, N, S_{z}, s 1, n$, and $\theta_{m}$ were sensitive to NIR, and the parameters LAI, $S_{L}, N, S_{z}$, $s 1, n, \theta_{m}$, and $C_{a b}$ were sensitive to RED (Figure 3 ). The hot spot parameter $S_{L}$ was approximately parameterized as a function of the LAI according to [6,45]. The parameter $n$ was sensitive to both NIR reflectance and RED reflectance, but their values were fixed because only the reed was considered. The parameters $\theta_{m}$ and $e_{l}$ were parameterized based on the field measurements of the leaf angle distribution. Therefore, the parameters LAI, $S_{L}, N, S_{z}$, and $s l$ were set as free parameters for the NIR reflectance-based LAI retrieval procedure, and LAI, $S_{L}, N, S_{z}, s 1$, and $C_{a b}$ were set as free parameters for the NDVI-based LAI retrieval procedure.

Figure 3. Sensitivity analysis of key input parameters of ACRM at near-infrared (NIR) and RED wavebands using Sobol's method. TSI stands for total sensitivity index.

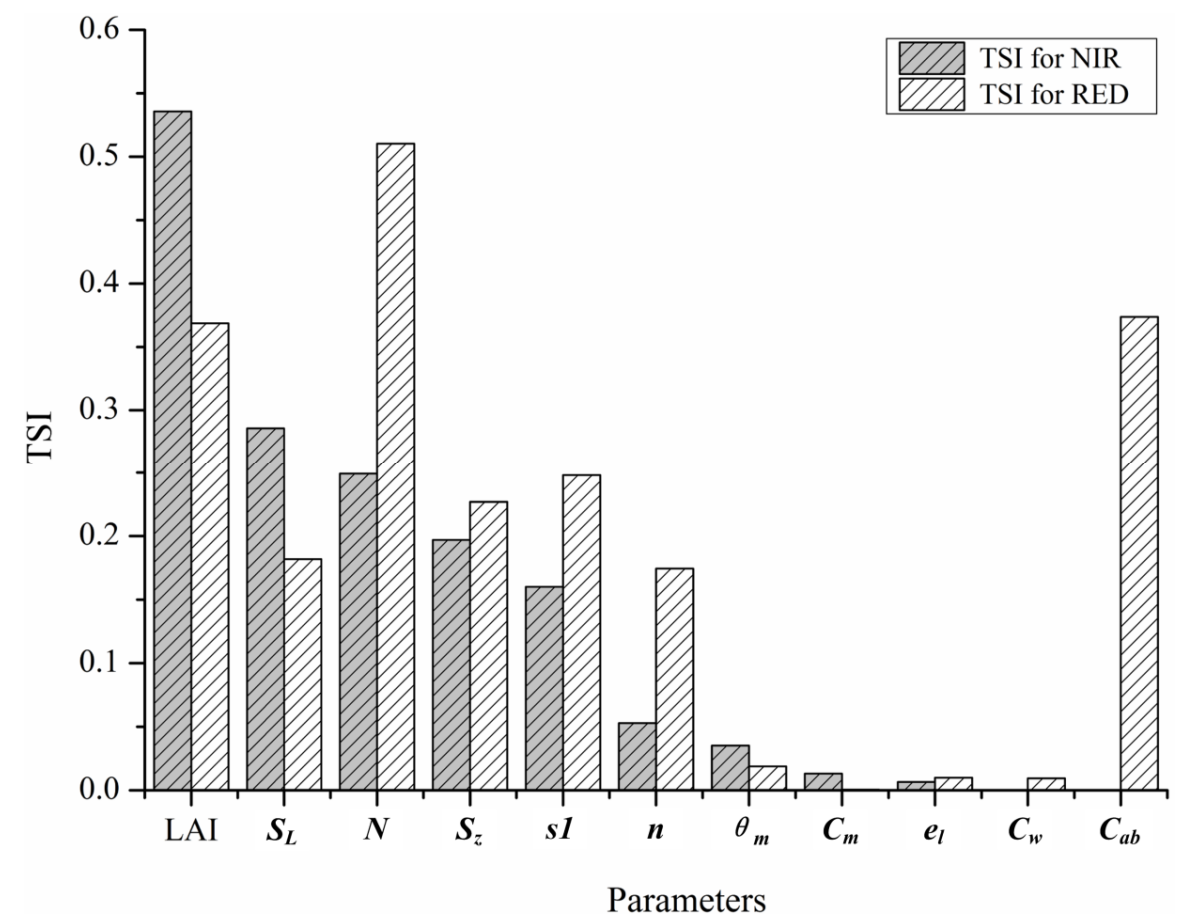

Based on the qualitative and quantitative priori information acquired from the field measurements, empirical values were used to determine the parameters that were insensitive to NIR and RED wavelengths (Table 1). The range and increment (dx) of the sensitive parameters (LAI, $N, s 1, S_{z}$, and $C_{a b}$ ) for the NDVI- and NIR-based LAI retrieval schemes are listed in Table 2. The LAI ranged from 0 to 4 for the NDVI-based LAI retrieval procedure and from 2 to 7 for the NIR-based LAI procedure (Section 2.1.2). As stated in Sections 2.1.1 and 2.4, $S_{z}$ was set from 0.4, which represents a significantly clumped plant canopy, to 1.0 , which represents a homogeneous, randomly positioned canopy. Soil with higher moisture content normally has low reflectance; thus, $s 1$ was set from 0.25 to 0.5 for sparse 
vegetation, where the soil typically has low soil moisture contents, and from 0.05 to 0.25 for dense vegetation, where the soil usually has high soil moisture contents. The range of $N$ was determined based on the priori information. Because $C_{a b}$ had no effect on NIR, $C_{a b}$ was treated as a free parameter for NDVI. Based on the priori information, $C_{a b}$ ranged from 30 to 90 based on priori information. The sets of LUTs for the NDVI and NIR image-based retrievals were 18,144 and 8,088, respectively. The cost function (Equation (11)) was used to access the optimal target parameters. Each symbol "/" in Table 1 means that the related parameter was sensitive and that its variability was confined (Table 2). Finally, the Sun zenith angle $\left(\theta_{s}\right)$, view zenith angle $\left(\theta_{v}\right)$, and relative azimuth angle $\left(\theta_{\mathrm{raz}}\right)$ parameters differed between pixels and were given in the MYD13 composite product.

Table 1. Inputs to the ACRM.

\begin{tabular}{cccc}
\hline Parameters & Units & Symbol & Value \\
\hline Sun zenith angle & $\left(^{\circ}\right)$ & $\theta_{s}$ & - \\
View zenith angle & $\left(^{\circ}\right)$ & $\theta_{v}$ & - \\
Relative azimuth angle & $\left(^{\circ}\right)$ & $\theta_{r a z}$ & - \\
Ángström turbidity coefficient & & $\beta$ & 0.12 \\
Leaf area index & $\mathrm{m}^{2} / \mathrm{m}^{2}$ & $\mathrm{LAI}$ & $/$ \\
LAI of ground level & $\mathrm{m}^{2} / \mathrm{m}^{2}$ & $\mathrm{LAI}_{\mathrm{g}}$ & 0.05 \\
Mean leaf angle of Elliptical LAD & $\left(^{\circ}\right)$ & $\theta_{l}$ & 60.0 \\
Hot spot parameter & & $S_{L}$ & $0.5 / \mathrm{LAI}$ \\
Markov clumping parameter & & $S_{z}$ & $/$ \\
Refractive index & & $n$ & 0.9 \\
Weight of the first basis function & & $s 1$ & $/$ \\
Leaf mesophyll structure & & $N$ & $/$ \\
Chlorophyll $a$ and $b$ content & $\mu \mathrm{g} \cdot \mathrm{cm}^{-2}$ & $C_{a b}$ & $/$ \\
Leaf equivalent water thickness & $\mathrm{cm}$ & $C_{W}$ & 0.015 \\
Dry matter content & $\mathrm{g} \cdot \mathrm{m}^{-2}$ & $C_{m}$ & 90 \\
Brown pigment & & $C_{b p}$ & 0.4 \\
\hline
\end{tabular}

Table 2. Ranges and steps ( $\mathrm{dx})$ of sensitive parameters in the ACRM for the NDVI and NIR image-based retrieval schemes.

\begin{tabular}{ccccc}
\hline Symbol & Range for NDVI-Based Retrieval Scheme & $\mathbf{d x}$ & Range for NIR-Based Retrieval Scheme & $\mathbf{d x}$ \\
\hline LAI & $0-4$ & 0.2 & $2-7$ & 0.2 \\
$S_{z}$ & $0.4-1.0$ & 0.2 & $0.4-1.0$ & 0.2 \\
$s 1$ & $0.25-0.5$ & 0.03 & $0.05-0.25$ & 0.03 \\
$N$ & $1.0-2.0$ & 0.2 & $1.5-2.5$ & 0.1 \\
$C_{a b}$ & $30-90$ & 20 & 60 & 0 \\
\hline
\end{tabular}

\subsection{Retrieved LAI on Each DOY}

The NDVI images from DOY 97 to 177 and from DOY 265 to 329 (the arid periods) were used to retrieve relatively lower LAI values, and both the NIR and NDVI images from DOY 185 to 257 were used to retrieve relatively higher LAI values to alleviate the influence of the soil background

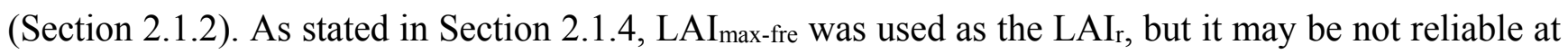


low values of $\varepsilon$. For example, in Figure $4 \mathrm{~b}, \mathrm{LAI}_{\text {mean }}$ was 0.49 , whereas LAImax-fre was 0 . This singular case was avoided in Figure $4 \mathrm{c}$, where $\varepsilon=0.05$. However, if the value of $\varepsilon$ was set too high, the retrieval scheme would be meaningless because the uncertainty in the LAIr values would increase as well (Equation (11)). In Figure 4d-f, as $\varepsilon$ increases, the LAI distribution approached a normal distribution. In the case shown in Figure 4f, LAImean or LAImax-fre can be regarded as the LAIr. However, if the LAI was near the boundaries of the given range, $\mathrm{LAI}_{\text {mean }}$ and $\mathrm{LAI}_{\text {max-fre }}$ might differ greatly. For example, in Figure $4 \mathrm{i}, \mathrm{LAI}_{\text {mean }}=6.14$, whereas $\mathrm{LAI}_{\text {max-fre }}=7.0$ because the LAI distribution was no longer normally distributed. In this case, it was more reliable to set LAImax-fre as the LAIr, as was assumed in Section 2.1.4. Therefore, in the study, $\varepsilon=0.05$, and LAI $I_{\text {max-fre }}$ was set as the LAIr.

Figure 4. Distribution of LAIr. Because of the ill-posed inversion problem, LAIr is not a single value but a wide range of different frequencies.
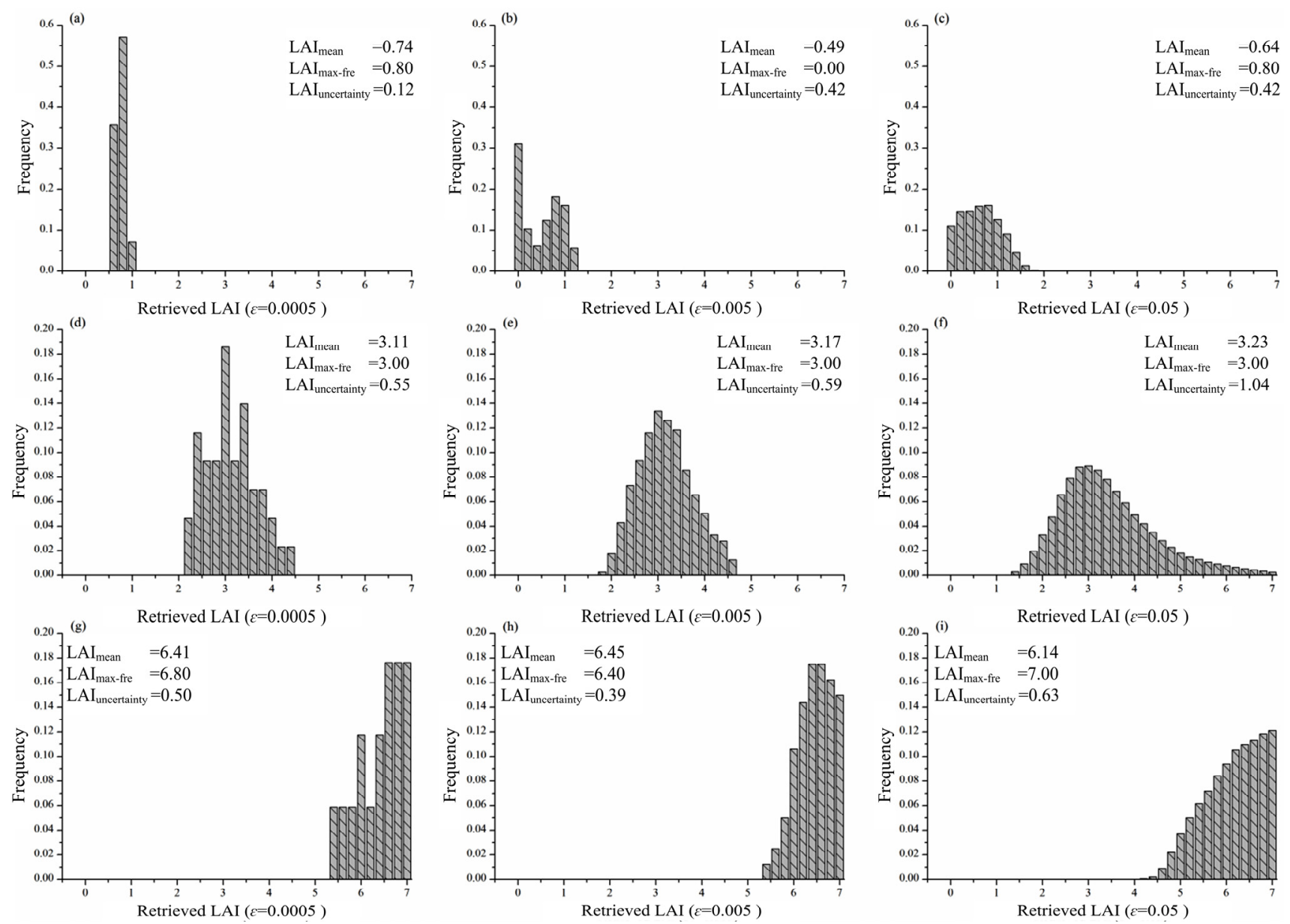

Figure 5a compares the $\mathrm{LAI}_{\mathrm{r}}$ and ground-measured $\mathrm{LAI}\left(\mathrm{LAI}_{\mathrm{m}}\right)$ values from July. The dashed line is the 1:1 line, and the solid line is the least-squares regression line. Of 38 points, the residual sum of squares (RSS), coefficient of determination $\left(\mathrm{R}^{2}\right)$, and root-mean-square error (RMSE) values were 3.47, 0.68 , and 0.31 , respectively. Because the points were clustered at low LAI values $(\leq 1.0)$, the RMSE value of 0.31 could signal a low level of precision of the retrieval. In August (Figure 5b), the LAI $\mathrm{I}_{\mathrm{r}}$ and LAIm points at high and low LAI values were less scattered than those in the middle range of LAI values. In other words, the LAI retrieval procedure might be more sensitive at the low and high ends of the LAI values. Of 46 points, the RSS, $\mathrm{R}^{2}$, and RMSE values were $38.96,0.73$, and 0.94 , respectively. The higher 
RSS and RMSE values in August compared to those in July could be caused by the increased LAI values as the reeds grew during this part of the year. This interpretation was supported by the high measured LAI values (Figure 5a,b). In summary, the LAIr values had large uncertainty in the retrieval; this is illustrated in Figure 6, where the peak LAIr values in the study period and from three pixels (locations) decrease from (a) to (b) to (c). Therefore, the LAIr values were smoothed to attempt to improve the precision level of $\mathrm{LAI}_{\mathrm{r}}$.

Figure 5. LAIr compared to the field-measured LAI on DOY 177 (July) (a) and DOY 233 (August) (b) in 2011.
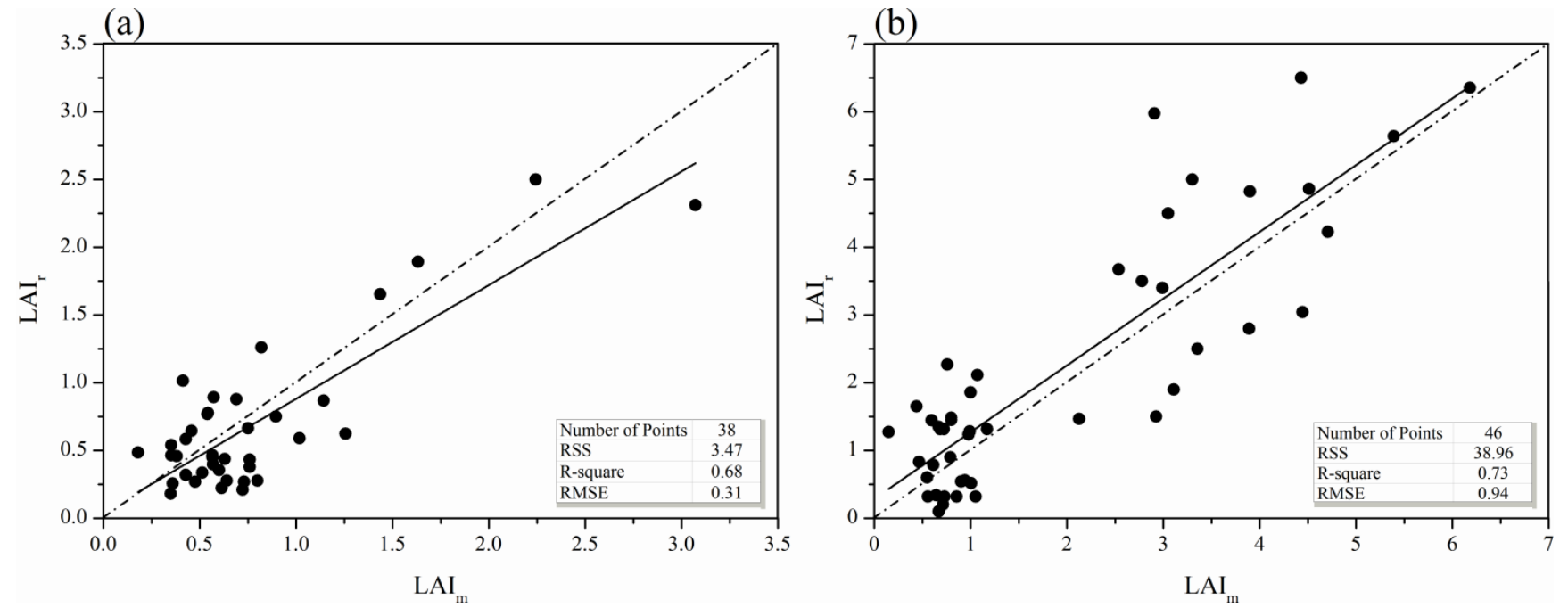

\subsection{Smoothing the LAI Curves Using the Fourier Model}

As previously discussed, the Fourier model can remove singular points in time series. For example, in Figure 6a,b, the LAI should not decrease from DOY 209 to 241 because the reeds were in the growth stage. In Figure 6c, the decrease in LAI value at DOY 209 could be another singular point. The LAIr values were then smoothed using the polynomial included in the Fourier model (Equation (14)). Figure $7 \mathrm{a}-\mathrm{c}$ shows the data from Figure $6 \mathrm{a}-\mathrm{c}$ after the smoothing that was performed. Clearly, the singular points identified in Figure $6 \mathrm{a}-\mathrm{c}$ were removed. The LAI fitted by the Fourier model (LAIF) and LAIm were then compared again. Of the 38 points from July (Figure $8 \mathrm{a}$ ), the RSS, $\mathrm{R}^{2}$, and RMSE values were 3.42, 0.67, and 0.3, respectively. Of the 46 points from August (Figure 8b), the RSS, $\mathrm{R}^{2}$, and RMSE values were 29.25, 0.77, and 0.81, respectively. Compared to the July data, the precision of the $\mathrm{LAI}_{\mathrm{r}}$ assessed by the RSS, $\mathrm{R}^{2}$, and RMSE values were similar before and after the Fourier model smoothing. No meaningful improvement in the precision was achieved for the LAIr values. The precision level of the August LAIr data might have improved after the Fourier smoothing based on the decrease in the RSS and RSME values and the increase in $\mathrm{R}^{2}$ value compared with the values before the smoothing, but the improvement was slight. The extended Fourier approach was investigated next to determine whether the approach could increase the precision level in a meaningful way. 
Figure 6. LAIr versus day of year (DOY) for three pixels. The solid line is the LAIr, and the error bars on each DOY represent LAIuncertainty. (a) and (b) are the LAIr of vegetation near Wutumeiren river; (c) is the LAIr of vegetation in drought area. The peak LAIr values in the study period decrease from (a) to (b) to (c).
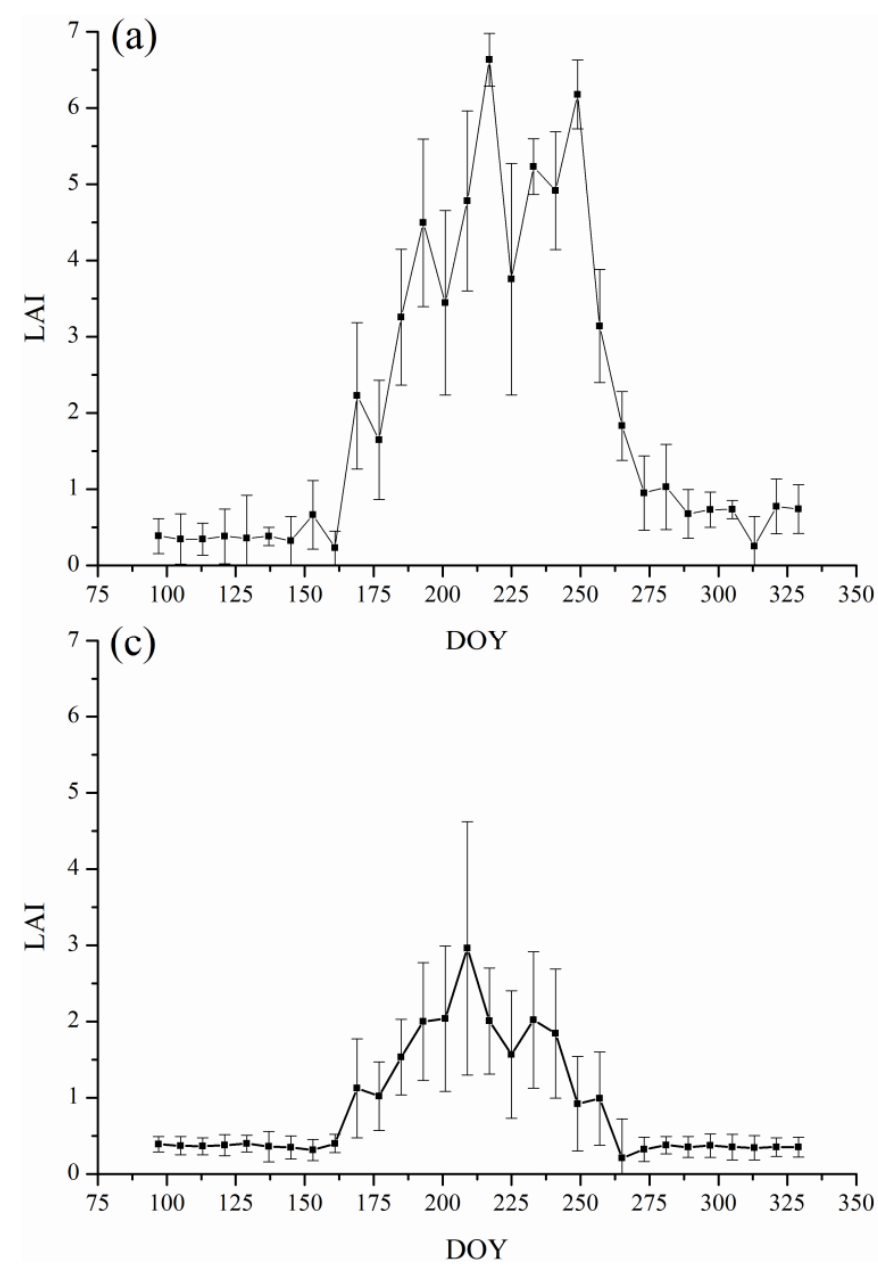

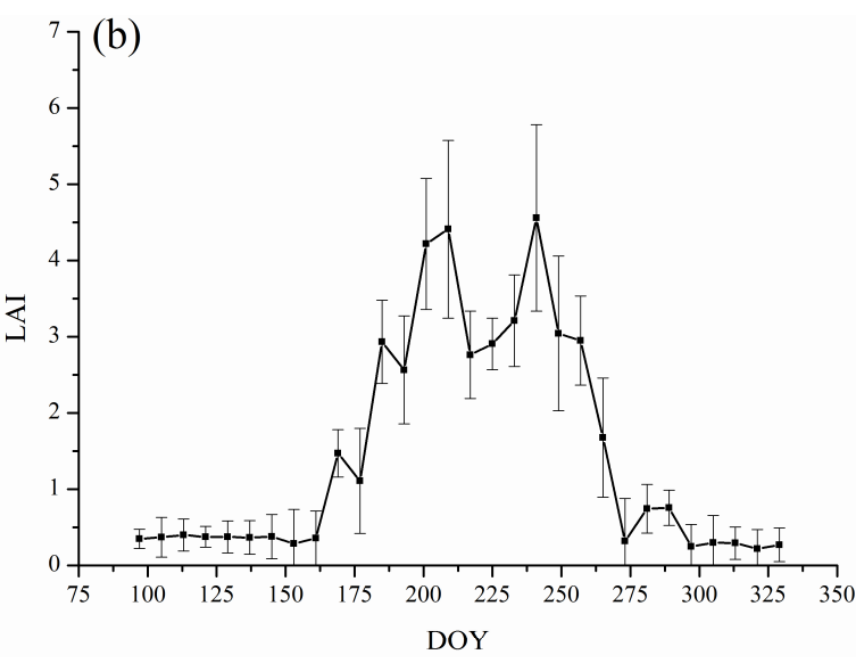

$\longrightarrow$ Retrieved LAI curves with uncertainty

Figure 7. Comparison of the $\mathrm{LAI}_{\mathrm{r}}$ and $\mathrm{LAI}_{\mathrm{F}}$ for three pixels from dense vegetation to sparse vegetation in the time series. (a) and (b) are the LAI $\mathrm{r}$ of vegetation near Wutumeiren river; (c) is the LAIr of vegetation in drought area.
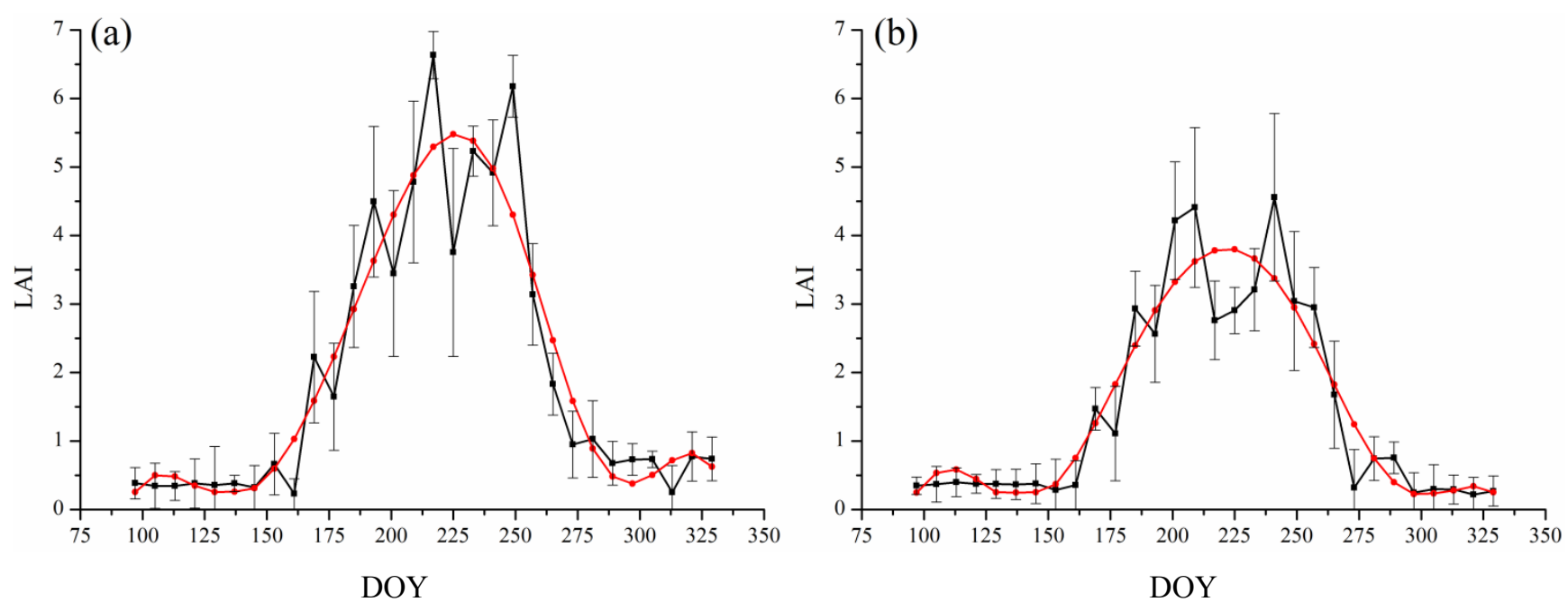
Figure 7. Cont.

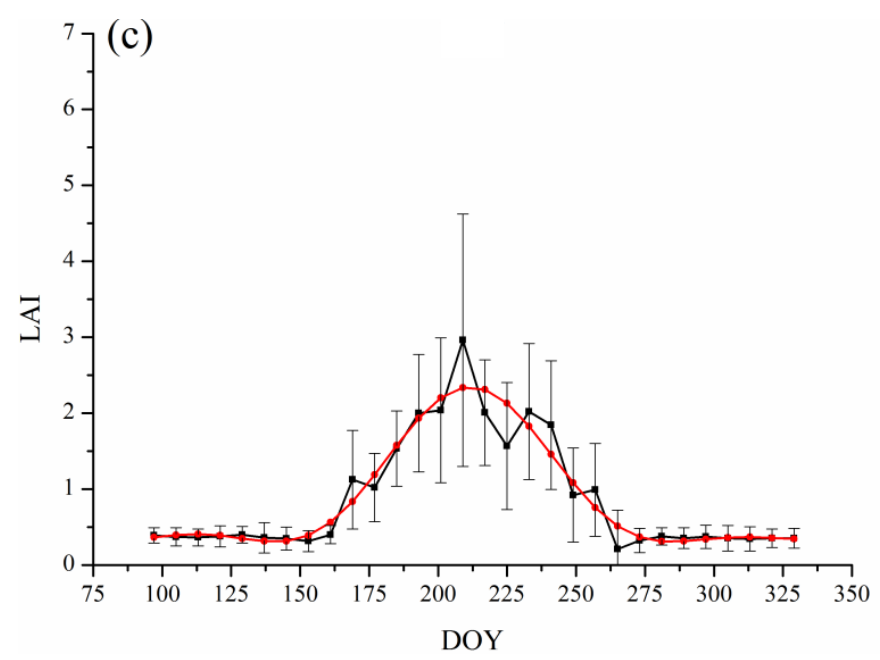

$\longrightarrow$ Retrieved LAI curves with uncertainty

$\longrightarrow$ - Fitted LAI curves using Fourier model

Figure 8. Results of LAIF compared to LAIr in early July (a) and late August (b) 2011.
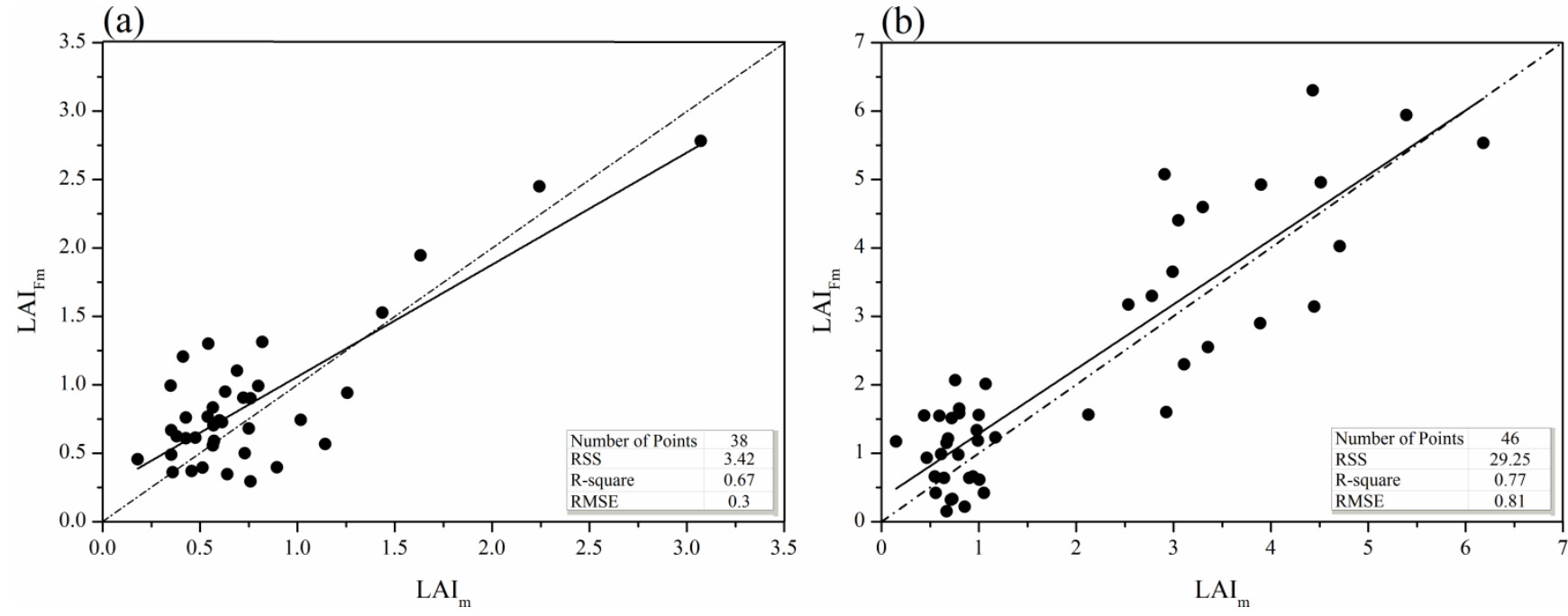

\subsection{Improving the LAI Curves Using the Extended Fourier Approach}

As shown in Figure 9, the LAIr curves were also smoothed using the extended Fourier approach ( $\mathrm{LAI}_{e}$ ), but the shapes of the $\mathrm{LAI}_{\mathrm{F}}$ and $\mathrm{LAI}_{e}$ curves were different. The $\mathrm{LAI}_{e}$ curves were farther away from the LAIr points with higher uncertainty and were closer to the LAIr points with lower uncertainty. For example, in Figure 9a, the LAIr value had a much lower uncertainty on DOY 217 than on DOY 225. The LAI ef curve was similar to the LAIr value on DOY 217 but far from that on DOY 225. Figure 9b,c had similar characteristics, but the LAIF curves did not. The LAIeF and LAIm values were then compared again (Figure 10). For the 38 points in July (Figure 10a), the RSS, $\mathrm{R}^{2}$, and RMSE values were 3.15, 0.72 , and 0.29 , respectively. For the 46 points in August (Figure 10b), the RSS, ${ }^{2}$, and RMSE values were $27.48,0.79$, and 0.78 , respectively. The precision level of the LAIeF values was improved compared with the $\mathrm{LAI}_{\mathrm{r}}$ and LAIF (Table 3). Therefore, the extended Fourier approach not only smoothed the LAIr curves in the time series but also improved the precision level of the LAI $\mathrm{I}_{\mathrm{r}}$ values by taking into account the uncertainty in the LAIr. 
Figure 9. Comparison between the $\mathrm{LAI}_{\mathrm{r}}, \mathrm{LAI}_{\mathrm{F}}$, and $\mathrm{LAI}_{\mathrm{eF}}$ values of three pixels from dense vegetation to sparse vegetation in the time series. (a) and (b) are the LAIr of vegetation near Wutumeiren river; $(\mathbf{c})$ is the LAIr of vegetation in drought area.
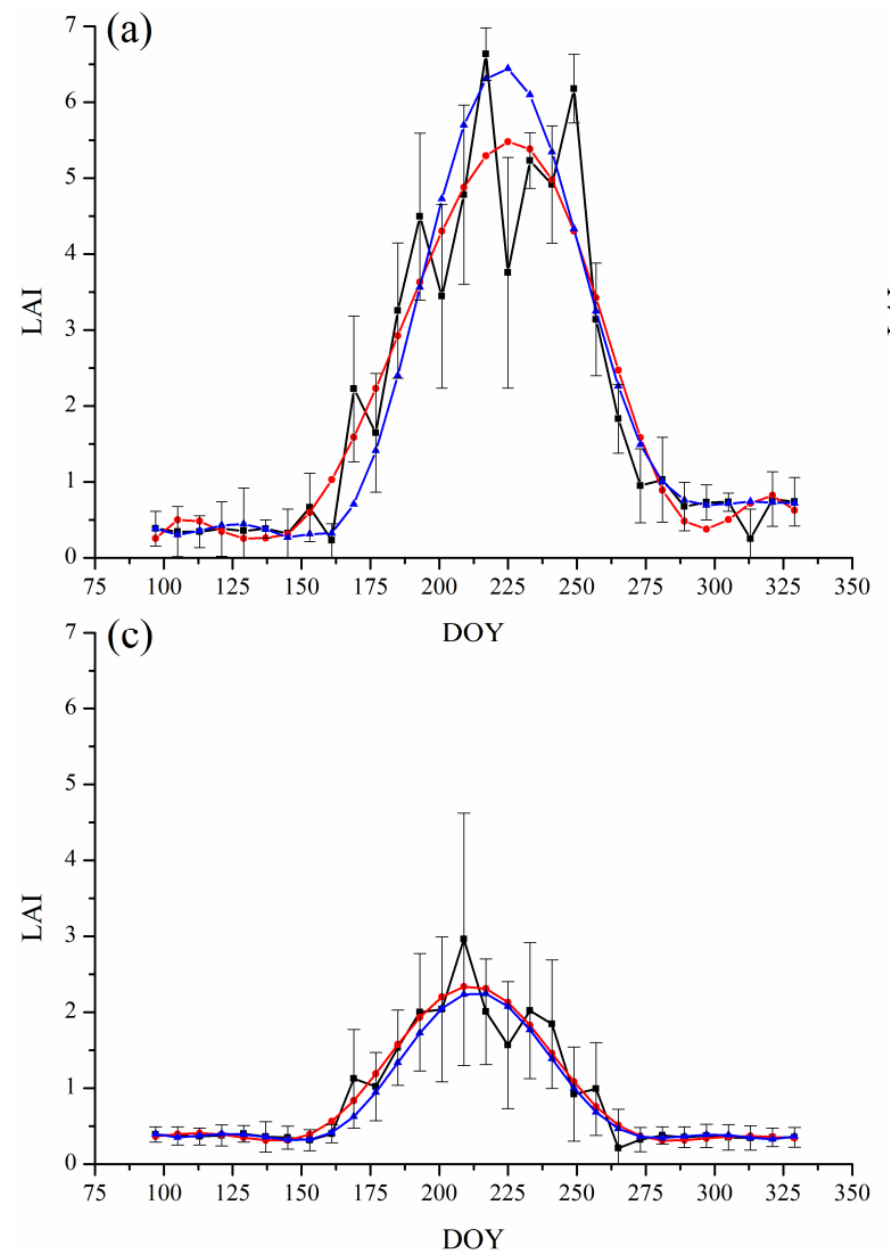

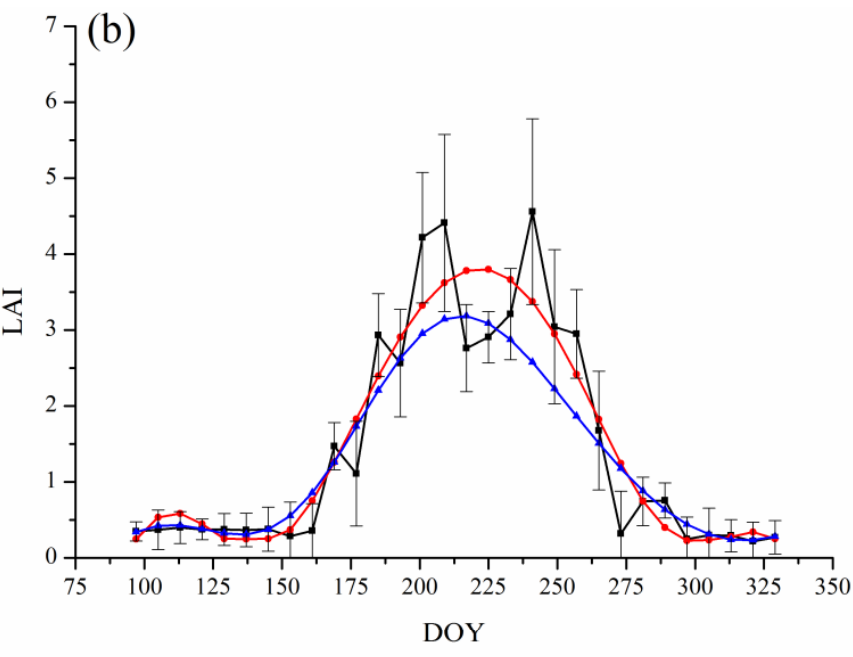

$\longrightarrow$ Retrieved LAI curves with uncertainty —— Fitted LAI curves using Fourier model Fitted LAI curves using extended Fourier approach

Figure 10. Results of the LAIe Falues compared to the LAIm values in early July (a) and late August (b) 2011.
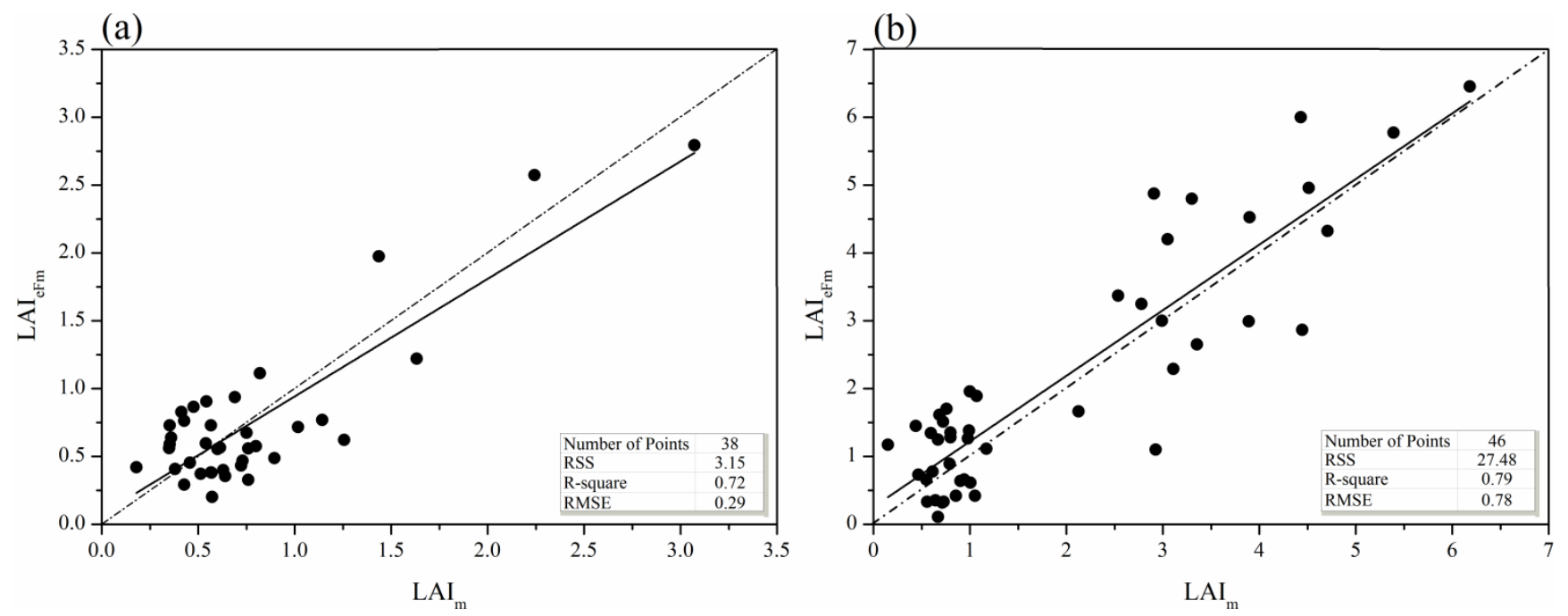
Table 3. Levels of precision of LAIr, LAIF, and LAIeF compared to LAIm on DOY 177 and 233.

\begin{tabular}{lcccc}
\hline & & RSS & R-Square & RMSE \\
\hline DOY 177 & LAI $_{\mathrm{r}}$ & 3.47 & 0.68 & 0.31 \\
& LAI $_{\mathrm{F}}$ & 3.42 & 0.67 & 0.30 \\
& $\mathrm{LAI}_{\mathrm{eF}}$ & 3.15 & 0.72 & 0.29 \\
\hline DOY 233 & $\mathrm{LAI}_{\mathrm{r}}$ & 38.96 & 0.73 & 0.94 \\
& $\mathrm{LAI}_{\mathrm{F}}$ & 29.25 & 0.77 & 0.81 \\
& $\mathrm{LAI}_{\mathrm{eF}}$ & 27.48 & 0.79 & 0.78 \\
\hline
\end{tabular}

\section{Discussion}

The Fourier model can be used to simulate the variation of LAI values in a time series. The Fourier model includes 11 free variables, which are fitted by the LAI $\mathrm{r}$ at different periods and the least squares method. However, the set of free variables in the Fourier model is much smaller than that in physical dynamic models, such as crop growth models. Physical dynamic models can better simulate the growth of crops because they are structured based on the physical mechanisms of vegetation growth. However, more work needs to be done on the selection of the appropriate model to simulate or approximate the growth of wild plants in alpine wetlands and to determine the large sets of input parameters. Therefore, it is infeasible to use a physical dynamic model to improve LAI estimates.

The Fourier model has been widely used to smooth the curves of parameters that are periodic. However, the model might not improve the precision level of the dataset. In this study, the Fourier model used in the fitting process was extended by taking into account the uncertainty in the LAIr values. As explained in Section 4.4, the improved fitted curves will be close to the points that have lower uncertainty and avoid points with larger uncertainty. The LAI $\mathrm{r}$ will have the best results and the precision level should be improved. As in the Fourier model, the extended Fourier approach can be used if the dataset is periodic, but the model will improve the precision of the dataset only if the uncertainty in the dataset is expressed correctly.

The LAI uncertainty imported in Equation (17) is regarded as the uncertainty caused by the ill-posed inversion problem. It can be used as an indicator to represent the uncertainty in the retrieval results as analyzed in Section 2.3. However, it may not describe the absolute uncertainty in the LAIr values because the uncertainty is affected by many factors, such as cloud cover, the LAI retrieval algorithm, and the ill-posed inversion problem.

\section{Concluding Remarks}

Characterized by high altitude and cold and dry weather, the alpine wetland is extremely fragile and vulnerable. The vegetation is typically composed of a single type of annual herb. In this study, an extended Fourier approach was presented to improve the LAI values in a 2011 time series from an alpine wetland located in western China. The LAI was retrieved on DOYs based on the ACRM, the MYD09Q1 product from DOY 97 to 297, and the LUT algorithm. To alleviate the ill-posed inversion problem, three strategies were implemented. (I) To reduce the influence of the soil background, the NDVI and NIR reflectance of wavebands were used to retrieve the LAI for sparse vegetation and dense vegetation, respectively; (II) A sensitivity analysis of the ACRM in the RED and NIR wavelengths was 
performed to determine the free parameters using Sobol's method; (III) The priori information was imported to constrain the range of free parameters in the ACRM. The LAIr in the time series did not form smooth curves due to the effects of the ill-posed inversion problem. A normalized Fourier model with two additional polynomials was used to smooth the LAIr curves in the time series because of the periodicity of the vegetation in the study area. The Fourier model is able to improve the level of precision of the $\mathrm{LAI}_{\mathrm{r}}$ if singular points are present, but it may also reduce the level of precision if the datasets that the model is based on contain large uncertainty. An extended Fourier approach was presented by taking into account the uncertainty in the LAIr in the Fourier model to improve the level of precision of the $\mathrm{LAI}_{\mathrm{r}}$. The $\mathrm{LAI}_{\mathrm{r}}, \mathrm{LAI}_{\mathrm{F}}$, and $\mathrm{LAI}_{\mathrm{eF}}$ values were validated through a comparison with field measured LAI ( $\mathrm{LAI}_{\mathrm{m}}$ ) values, which resulted in $\mathrm{R}^{2}$ values of $0.68,0.67$ and 0.72 , RSS values of 3.47, 3.42 and 3.15, and RMSE values of 0.31, 0.30 and 0.29, respectively, on DOY 177 (early July). On DOY 233 (late August), the $\mathrm{R}^{2}$ values were 0.73, 0.77 and 0.79, the RSS values were 38.96, 29.25 and 27.48, and the RMSE values were $0.94,0.81$ and 0.78 , respectively. The results demonstrated that this approach has the potential to improve the level of precision of periodically varying parameters in a time series.

\section{Acknowledgments}

This work was funded by the Fundamental Research Funds for the Central Universities (No. ZYGX2012Z005) and the National High-Tech Research and Development Program of China (863 Program, No. 2013AA12A302). The authors are grateful to Yongshuai Yan, Bo Zhang, Hongzhang Dai, Xiaojing Bai and Ningning Wang for their assistance during the field campaigns.

\section{Author Contributions}

Xingwen Quan designed and performed experiments, analysed data, and wrote the manuscript; Binbin He gave comments and suggestions to the manuscript and performed the experiments; Yong Wang commented the manuscript and checked the writing; Zhi Tang and Xing Li performed part of the experiments.

\section{Conflicts of Interest}

The authors declare no conflict of interest.

\section{References}

1. Houborg, R.; Soegaard, H.; Boegh, E. Combining vegetation index and model inversion methods for the extraction of key vegetation biophysical parameters using Terra and Aqua MODIS reflectance data. Remote Sens. Environ. 2007, 106, 39-58.

2. Fensholt, R.; Sandholt, I.; Rasmussen, M.S. Evaluation of MODIS LAI, FAPAR and the relation between FAPAR and NDVI in a semi-arid environment using in situ measurements. Remote Sens. Environ. 2004, 91, 490-507.

3. Xiao, Z.; Liang, S.; Wang, J.; Jiang, B.; Li, X. Real-time retrieval of leaf area index from MODIS time series data. Remote Sens. Environ. 2011, 115, 97-106. 
4. Darvishzadeh, R.; Skidmore, A.; Schlerf, M.; Atzberger, C. Inversion of a radiative transfer model for estimating vegetation LAI and chlorophyll in a heterogeneous grassland. Remote Sens. Environ. 2008, 112, 2592-2604.

5. Doraiswamy, P.; Hatfield, J.; Jackson, T.; Akhmedov, B.; Prueger, J.; Stern, A. Crop condition and yield simulations using Landsat and MODIS. Remote Sens. Environ. 2004, 92, 548-559.

6. Houborg, R.; Anderson, M.; Daughtry, C. Utility of an image-based canopy reflectance modeling tool for remote estimation of LAI and leaf chlorophyll content at the field scale. Remote Sens. Environ. 2009, 113, 259-274.

7. Meroni, M.; Colombo, R.; Panigada, C. Inversion of a radiative transfer model with hyperspectral observations for LAI mapping in poplar plantations. Remote Sens. Environ. 2004, 92, 195-206.

8. Colombo, R.; Bellingeri, D.; Fasolini, D.; Marino, C.M. Retrieval of leaf area index in different vegetation types using high resolution satellite data. Remote Sens. Environ. 2003, 86, 120-131.

9. Combal, B.; Baret, F.; Weiss, M.; Trubuil, A.; Mace, D.; Pragnere, A.; Myneni, R.; Knyazikhin, Y.; Wang, L. Retrieval of canopy biophysical variables from bidirectional reflectance: Using priori information to solve the ill-posed inverse problem. Remote Sens. Environ. 2003, 84, 1-15.

10. Combal, B.; Baret, F.; Weiss, M. Improving canopy variables estimation from remote sensing data by exploiting ancillary information. Case study on sugar beet canopies. Agronomie 2002, 22, 205-215.

11. Hermance, J.F.; Jacob, R.W.; Bradley, B.A.; Mustard, J.F. Extracting phenological signals from multiyear AVHRR NDVI time series: Framework for applying high-order annual splines with roughness damping. IEEE Trans. Geosci. Remote Sens. 2007, 45, 3264-3276.

12. Moody, A.; Johnson, D.M. Land-surface phenologies from AVHRR using the discrete fourier transform. Remote Sens. Environ. 2001, 75, 305-323.

13. Carrão, H.; Gonalves, P.; Caetano, M. A nonlinear harmonic model for fitting satellite image time series: Analysis and prediction of land cover dynamics. IEEE Trans. Geosci. Remote Sens. 2010, 48, 1919-1930.

14. Roerink, G.; Menenti, M.; Verhoef, W. Reconstructing cloudfree NDVI composites using Fourier analysis of time series. Int. J. Remote Sens. 2000, 21, 1911-1917.

15. Geerken, R.; Zaitchik, B.; Evans, J. Classifying rangeland vegetation type and coverage from NDVI time series using Fourier filtered cycle similarity. Int. J. Remote Sens. 2005, 26, 5535-5554.

16. Brooks, E.B.; Thomas, V.A.; Wynne, R.H.; Coulston, J.W. Fitting the multitemporal curve: A fourier series approach to the missing data problem in remote sensing analysis. IEEE Trans. Geosci. Remote Sens. 2012, 50, 3340-3353.

17. Bach, H.; Mauser, W. Methods and examples for remote sensing data assimilation in land surface process modeling. IEEE Trans. Geosci. Remote Sens. 2003, 41, 1629-1637.

18. Seo, D.-J.; Cajina, L.; Corby, R.; Howieson, T. Automatic state updating for operational streamflow forecasting via variational data assimilation. J. Hydrol. 2009, 367, 255-275.

19. Naud, C.; Makowski, D.; Jeuffroy, M.-H. Application of an interacting particle filter to improve nitrogen nutrition index predictions for winter wheat. Ecol. Model. 2007, 207, 251-263.

20. Van Leeuwen, P.J. A variance-minimizing filter for large-scale applications. Mon. Wea. Rev. 2003, 131, 2071-2084. 
21. Smith, P.J.; Dance, S.L.; Nichols, N.K. A hybrid data assimilation scheme for model parameter estimation: Application to morphodynamic modelling. Comput. Fluids 2011, 46, 436-441.

22. Van Velzen, N.; Segers, A. A problem-solving environment for data assimilation in air quality modelling. Environ. Model. Softw. 2010, 25, 277-288.

23. Rudd, A.; Roulstone, I.; Eyre, J. A simple column model to explore anticipated problems in variational assimilation of satellite observations. Environ. Model. Softw. 2012, 27, 23-39.

24. Tripathy, R.; Chaudhari, K.N.; Mukherjee, J.; Ray, S.S.; Patel, N.; Panigrahy, S.; Parihar, J.S. Forecasting wheat yield in Punjab state of India by combining crop simulation model WOFOST and remotely sensed inputs. Remote Sens. Lett. 2012, 4, 19-28.

25. Confalonieri, R.; Acutis, M.; Bellocchi, G.; Donatelli, M. Multi-metric evaluation of the models WARM, CropSyst, and WOFOST for rice. Ecol. Model. 2009, 220, 1395-1410.

26. Marin, F.R.; Jones, J.W.; Royce, F.; Suguitani, C.; Donzeli, J.L.; Wander Filho, J.P.; Nassif, D.S.P. Parameterization and evaluation of predictions of DSSAT/CANEGRO for brazilian sugarcane. Agron. J. 2011, 103, 304-315.

27. Van Dam, J.C.; Groenendijk, P.; Hendriks, R.F.A.; Kroes, J.G. Advances of modeling water flow in variably saturated soils with swap. Vadose Zone J. 2008, 7, 640-653.

28. Kalnay, E.; Li, H.; Miyoshi, T.; Yang, S.C.; Ballabrera-poy, J. 4-D-Var or ensemble kalman filter? Tellus A 2007, 59, 758-773.

29. Jakubauskas, M.E.; Legates, D.R.; Kastens, J.H. Harmonic analysis of time-series AVHRR NDVI data. Photogramm. Eng. Remote Sens. 2001, 67, 461-470.

30. Hermance, J.F. Stabilizing high-order, non-classical harmonic analysis of NDVI data for average annual models by damping model roughness. Int. J. Remote Sens. 2007, 28, 2801-2819.

31. Tucker, C.J. Red and photographic infrared linear combinations for monitoring vegetation. Remote Sens. Environ. 1979, 8, 127-150.

32. Sobol, I.M. Sensitivity estimates for nonlinear mathematical models. Math. Model. Comput. Exp. 1993, 1, 407-414.

33. Kuusk, A. A two-layer canopy reflectance model. J. Quant. Spectrosc. Radiat. Transf. 2001, 71, $1-9$.

34. Iqbal, M. An Introduction to Solar Radiation; Academic Press: Toronto, ON, Canada, 1983.

35. Price, J.C. On the information content of soil reflectance spectra. Remote Sens. Environ. 1990, 33, 113-121.

36. Kuusk, A. A multispectral canopy reflectance model. Remote Sens. Environ. 1994, 50, 75-82.

37. Campbell, G. Derivation of an angle density function for canopies with ellipsoidal leaf angle distributions. Agric. For. Meteorol. 1990, 49, 173-176.

38. Liang, S. Quantitative Remote Sensing of Land Surfaces; John Wiley and Sons, Inc.: New York, NY, USA, 2004.

39. Kuusk, A. A Markov chain model of canopy reflectance. Agric. For. Meteorol. 1995, 76, 221-236.

40. Jacquemoud, S.; Baret, F. Prospect: A model of leaf optical properties spectra. Remote Sens. Environ. 1990, 34, 75-91.

41. Nossent, J.; Elsen, P.; Bauwens, W. Sobol'sensitivity analysis of a complex environmental model. Environ. Model. Softw. 2011, 26, 1515-1525. 
42. Glen, G.; Isaacs, K. Estimating sobol sensitivity indices using correlations. Environ. Model. Softw. 2012, 37, 157-166.

43. Homma, T.; Saltelli, A. Importance measures in global sensitivity analysis of nonlinear models. Reliab. Eng. Syst. Saf. 1996, 52, 1-17.

44. He, B.; Quan, X.; Xing, M. Retrieval of leaf area index in alpine wetlands using a two-layer canopy reflectance model. Int. J. Appl. Earth Obs. Geoinf. 2013, 21, 78-91.

45. Verhoef, W.; Bach, H. Simulation of hyperspectral and directional radiance images using coupled biophysical and atmospheric radiative transfer models. Remote Sens. Environ. 2003, 87, 23-41.

(C) 2014 by the authors; licensee MDPI, Basel, Switzerland. This article is an open access article distributed under the terms and conditions of the Creative Commons Attribution license (http://creativecommons.org/licenses/by/3.0/). 